Ciência Florestal, Santa Maria, v. 22, n. 3, p. 589-603, jul.-set., 2012

ISSN 0103-9954

\title{
AS UNIDADES DE CONSERVAÇÃO E A FLORESTA OMBRÓFILA MISTA NO ESTADO DO PARANÁ
}

\author{
PROTECTED AREAS AND MIXED OMBROPHYLOUS FOREST IN PARANÁ STATE
}

Paulo de Tarso de Lara Pires ${ }^{1}$ Douglas Magnus Zeni Junior ${ }^{2}$ Debora Gaulke ${ }^{3}$

\section{RESUMO}

O intenso processo de ocupação territorial, uso desordenado dos recursos naturais e destruição de áreas verdes iniciadas no século XIX, são os principais motivos da intensa devastação das Florestas com Araucárias. Como meio de efetivação da proteção e desenvolvimento florestal, o Brasil adotou em sua política ambiental a criação do Sistema de Unidades de Conservação nas categorias, de proteção integral e uso sustentável. Uma alternativa viável é a regulação dos estoques de madeira no Estado por meio de Unidade de Conservação de Uso Sustentável. O que se pretende a partir deste ponto é analisar a possibilidade da criação de regulamentação do aproveitamento dos recursos naturais em espaços naturais protegidos. Para tanto, foram selecionadas e trabalhadas duas modalidades de Unidades de Conservação (UC), já existentes, e proposta a criação de uma nova modalidade, então denominada "Reservas Particulares de Desenvolvimento Sustentável (RPDS)". As Unidades de Proteção Integral têm desempenhado papel expressivo na preservação do Bioma Florestal com Araucária. Em contrapartida, as Unidades de Conservação de Uso Sustentável são inexpressivas no Bioma e necessitam de uma efetiva regulamentação para que desempenhem sua função ecológica e social. Medidas de incentivo à conservação das florestas particulares e ao uso sustentável dos recursos madeireiros e não madeireiros, somadas ao instrumental atualmente utilizado, podem contribuir com maior efetividade na conservação e recuperação do Bioma Florestal com Araucária.

Palavras-chave: floresta de araucária; araucária; unidades de conservação.

\begin{abstract}
The intense process of territorial occupation, the unsustainable use of natural resources and the destruction of green areas throughout the nineteenth century are the main reasons for the intense devastation of Mixed Ombrophylous Forest. In an effort to forestry protection and its development, Brazil has adopted as one of its environmental policy, the creation of the Conservation Units System. However, an alternative still rarely used for the regulation of stockpiles timber in the state is by means of the Conservation Unit of Sustainable Use. At this point, it is intended to propose a regulated use for natural resources in protected natural areas. Therefore, two forms of existing Conservation Units were selected to this end it has been proposed the creation of a new modality, called "Private Reserves for Sustainable Development (RPDS)." The Integral Protection Units have played significant role in preserving the biome of Mixed Ombrophylous Forest. In contrast, the Sustainable Use Conservation Units are inexpressive in the biome and need an effective regulation to perform their ecological and social function. Measures to encourage private forests conservation and the sustainable use of timber and non-timber resources, in addition to the instrumental currently used, may contribute being greatly effective in the conservation and recovery of the biome.
\end{abstract}

Keywords: Mixed Ombrophylous Forest; Parana pine; protected areas.

1. Engenheiro Florestal, Dr., Advogado, Professor Adjunto do Departamento de Economia Rural e Extensão, Setor de Ciências Agrárias, Universidade Federal do Paraná, Rua dos Funcionários, 1540, Juvevê, CEP 80035-050, Curitiba (PR).ptlpires@ufpr.br

2. Engenheiro Florestal.dmzjr@hotmail.com

3. Engenheira Florestal, Acadêmica do Curso de Pós-graduação MBA em Gestão Ambiental,Universidade Federal do Paraná, Rua dos Funcionários, 1540, Juvevê, CEP 80035-050, Curitiba (PR). debora.gaulke@gmail.com

Recebido para publicação em 15/10/2008 e aceito em 27/05/2011 


\section{INTRODUÇÃO}

A humanidade atravessa uma fase de transição e conflitos para ultrapassar obstáculos criados pela civilização contemporânea. A descoberta de novas tecnologias leva o homem a desencadear, principalmente a partir dos séculos XIX e XX, um intenso processo de ocupação territorial. Dessa maneira, os remanescentes florestais do Brasil prosseguem sendo devastados, como é o caso da Floresta com Araucária na região sul, em que sua destruição ocorreu de forma intensa, ocasionando seu auge na segunda metade do século passado. Tendo como bandeira a abertura de novas fronteiras agrícolas, a geração de novos empregos e o desenvolvimento social, espécies florestais preciosas vêm sendo dizimadas.

As florestas de Araucária, de ocorrência predominante na região Sul do país, são de alta relevância econômica, oferecem diversos recursos madeireiros e outros produtos da floresta, além de ser considerado símbolo para a região e forma de vínculo afetivo para o seu povo.

De acordo com Maack (1968), o Estado do Paraná possuía cerca de $83 \%$ da superfície originalmente coberta por uma exuberante vegetação, hoje tem sua área florestal reduzida a aproximadamente $5 \%$ do território. A necessidade de se intensificar os estudos florestais no Estado é evidente, desta maneira, esse trabalho tem como foco contribuir para a melhoria da gestão florestal nesse Bioma.

Ademais, advoga-se neste trabalho a tese de que esta categoria Unidades de Uso Sustentável (UUS), ainda pouco utilizada no Brasil, pode ser uma alternativa para a regulação dos estoques de madeira no Estado. No entanto, tudo indica que uma solução definitiva dependerá também do reconhecimento, em termos econômicos, do valor dos benefícios, ou externalidades ambientais, oriundos dos ecossistemas naturais, tais como: a fixação do carbono, a conservação da biodiversidade, a provisão de água límpida, o lazer, entre tantos outros. O Governo do Estado pode, por meio de suas Florestas Estaduais e, com a autorização da União, também nas Florestas Nacionais, promover a pesquisa do manejo florestal sustentado da Araucária, bem como promover o comércio da madeira de forma alternativa e sustentável, tendo o enfoque maior na preservação do Bioma, aliado a um projeto social amplo com a população diretamente afetada.

O grande desafio é a busca por um programa de gestão florestal, que vislumbre a conservação e a recuperação dos remanescentes florestais de Araucária no Estado, sem onerar de forma excessiva a região de influência, nem refrear o crescimento econômico do setor agroflorestal regional.

As unidades de conservação são áreas especialmente protegidas para a conservação da natureza, permitindo preservar e manter a diversidade biológica local e, talvez, o mais importante, estabelecer um elo entre os principais remanescentes florestais.

AResolução $n^{\circ}$. 011/87 do CONAMA define as unidades de conservação como áreas naturais protegidas e sítios ecológicos com características naturais relevantes, de domínio público ou privado, legalmente instituídas pelo Poder Público para proteger a natureza, com objetivos e limites definidos e com regimes específicos de manejo e administração, aplicando-se garantias adequadas de proteção. Em complemento para a regulamentação desse dispositivo foi editada a Lei $\mathrm{n}^{\circ}$. 9.985/2000, que criou o Sistema Nacional de Unidades de Conservação (SNUC).

O Sistema Nacional de Unidades de conservação (SNUC) define e regulamenta as categorias de unidades de conservação, separandoas em dois grupos: áreas de proteção integral, destinadas principalmente à conservação da biodiversidade, e áreas de uso sustentável, que permitem o uso racional de recursos naturais, e têm como objetivo secundário a proteção à biodiversidade.

Unidades de conservação de proteção integral englobam estações ecológicas, reservas biológicas, parques nacionais, monumentos naturais e refúgios da vida silvestre. Nesses locais, qualquer atividade a ser realizada fica condicionada à autorização prévia do órgão responsável e deverá priorizar a manutenção do equilíbrio do ecossistema, sendo que as visitas públicas ficam restritas àquelas com objetivos educacionais e científicos.

As áreas particulares incluídas em seus limites, com exceção dos monumentos naturais e refúgios da vida silvestre, que podem ser constituídos também em áreas particulares, serão desapropriadas. Essa disposição é de caráter eminentemente preservacionista, pois não permite uso sustentável e necessita da tutela e financiamento quase exclusivos do Poder Público.

Unidades de conservação de uso sustentável objetivam compatibilizar a conservação da natureza com o uso sustentável dos recursos naturais. Estão 
incluídas nessa categoria as áreas de proteção ambiental, áreas de relevante interesse ecológico, florestas nacionais, reservas extrativistas, reservas de fauna, reservas de desenvolvimento sustentável, e reservas particulares do patrimônio natural, espaços onde, em tese, seria tolerado o uso racional dos recursos naturais existentes. Podem ser constituídas por terras públicas ou privadas, ficando condicionado o seu uso às normas estabelecidas pelo gestor público em unidades de domínio público e pelas condições estabelecidas pelo proprietário em unidades particulares.

Silva (1996) considera que as áreas de proteção são espaços destinados ao manejo sustentável, ou seja, aqueles que são submetidos a uma proteção parcial dos atributos naturais, admitida a exploração de partes dos recursos disponíveis em regime de manejo sustentado, sujeito às limitações legais. Porção representativa destas unidades de conservação abriga em seu interior ou nas zonas de amortecimento populações, comunidades, que, por vezes, dependem dos recursos naturais para sua sobrevivência.

Em âmbito nacional, o sistema de unidades de conservação é gerido em três instâncias: Órgão Consultivo (CONAMA), Órgão Central (Ministério do Meio Ambiente) e Órgãos Executores (Instituto Chico Mendes de Conservação da Biodiversidade - ICMBIO e Instituto Brasileiro do Meio Ambiente e dos Recursos Naturais Renováveis - IBAMA em conjunto com Órgãos Estaduais e Municipais). No Paraná, os órgãos que atuam na gestão das unidades de conservação são: a Secretaria Estadual do Meio Ambiente (órgão central), o CONSEMA (órgão consultivo) e o Instituto Ambiental do Paraná (órgão executor).

\section{Experiência nacional e internacional na gestão das unidades de conservação}

A legislação florestal norte-americana (traduzido) é um referencial importante no que diz respeito ao planejamento das Unidades de Conservação. A Subparte A do título 36 do Código de Regulamentações Federais trata do "Planejamento e Manejo das terras e recursos do Sistema Nacional de Florestas". De acordo com a seção "219.1-a", a regra jurídica tem como princípio a determinação da forma pela qual o planejamento e manejo dos recursos e das terras devem ser conduzidos no Sistema Nacional de Terras Florestais.

Além disso, o planejamento deve guiar todas as atividades de manejo de recursos naturais e estabelecer padrões de manejo e diretrizes para o Sistema Nacional de Florestas. Esta seção reconhece ainda que as Florestas Nacionais são ecossistemas fundamentais e o seu manejo para bens e serviços requer uma consciência e consideração das interrelações entre plantas, animais, solo, água, ar, e outros fatores ambientais envolvidos em tais ecossistemas.

A avaliação do Plano de Uso dos Recursos Florestais (RPA) deve incluir análise dos usos presentes e futuros, demanda e oferta de recursos da floresta, pastagens naturais, e outras terras associadas considerando a oferta, a demanda e as tendências de preços associados. Ainda, deve conter um inventário dos recursos naturais presentes e recursos naturais potenciais, e uma avaliação das oportunidades para melhorar a sua produção de bens e serviços tangíveis e intangíveis, juntamente com estimativas de custos de investimento e retornos financeiros diretos e indiretos para o Governo Federal.

O RPA inclui também a descrição dos programas de pesquisa do serviço florestal, programas cooperativos, manejo do Sistema Nacional de Florestas; análises políticas e legais, e de outros fatores que possam influenciar e afetar significativamente o uso, a posse, e o manejo das florestas, pastagens naturais, e outras terras associadas.

O Decreto $\mathrm{n}^{\circ} .1 .607 / 85$ da Bélgica trata dos chamados parques naturais. Para a lei belga, um parque natural é um território rural de alto interesse biológico e geográfico submetido às medidas destinadas a proteger o meio, em harmonia com as aspirações da população e o desenvolvimento econômico e social do território em questão. Os planos de manejo dos referidos parques devem indicar os objetivos no qual concerne notadamente a conservação da natureza, a proteção do meio ambiente, o desenvolvimento do território, o desenvolvimento rural e econômico.

O artigo 106 da Constituição da Venezuela impõe ao Estado o dever de atender à defesa e conservação dos recursos naturais de seu território, estabelecendo ainda que a exploração dos mesmos estará dirigida primordialmente ao benefício coletivo dos venezuelanos (Ley de Bosques y Gestión Forestal, 2008).

A Lei $n^{\circ}$. 76.629/1976 da França, Lei de Proteção Ambiental, também aborda a questão do impacto ambiental no planejamento. De acordo com o artigo 12, os trabalhos e projetos que são 
empreendidos por uma coletividade pública ou que necessitam de uma autorização, ou uma decisão de aprovação, assim como os documentos de urbanismo, devem respeitar os bens de interesse do ambiente. Segundo o mesmo artigo, o conteúdo do estudo de impacto deve compreender no mínimo uma análise do estado inicial do sítio e de seu ambiente, o estudo das modificações que o projeto causará e as medidas consideradas para suprimir, reduzir e, se possível, compensar as consequências danosas para o ambiente.

A Lei $n^{\circ} .4 / 89$ da Espanha prevê entre suas categorias de espaços protegidos os Parques Naturais, que são unidades de conservação onde se harmonizará a conservação dos valores naturais com o aproveitamento ordenado dos recursos florestais (BAQUERIZO, 1990). (Legislación Forestal, 2001).

Um mecanismo importante na gestão florestal é a criação de grupamentos de produtores florestais, a exemplo do previsto no Capítulo VIII da Lei $n^{\circ} .248$-1 da Lei Florestal Francesa, que dispõe: "As sociedades cooperativas e suas uniões, as sociedades de interesse agrícola coletivo, as associações e agrupamentos de proprietários florestais, constituídos para melhorar a produção das florestas ou para favorecer o fluxo dos produtos e regularizar os cursos, podem ser reconhecidos pelo representante do Estado na região, após parecer do centro regional da propriedade florestal, como agrupamentos de produtores florestais,... omissis".

O capítulo da referida lei é dedicado aos proprietários de florestas. No entanto, o mecanismo da formação de agrupamentos de produtores florestais poderia ser utilizado com sucesso em unidades de conservação de uso sustentável, uma vez que suas características recomendam a adoção de um mecanismo de gestão compartilhada.

Uma alternativa desejável é a existência de um sistema de gestão participativa. A Lei no 1 15.939 do Uruguai apresenta um instrumento em seu artigo 18 que possibilita a administração e direção dos parques para o público em geral (MERCOSUL, 1998).

A Lei Florestal da Bolívia (Lei $\mathrm{n}^{\circ}$. 1700/1996) prevê o regime de concessão florestal a grupamentos sociais locais. Segundo este dispositivo, os usuários tradicionais, as comunidades campesinas e os grupamentos sociais locais têm preferência na concessão de áreas com recursos tradicionais de extrativismo (MERCOSUL - Legislação, 1998).

Por razões de conveniência, o Poder Executivo poderá conceder a entidades públicas ou privadas sem fins lucrativos, a direção e administração de outros setores do Patrimônio Florestal do Estado. No caso dos parques nacionais o uso deverá ser permitido para o público em geral. As comunidades locais organizadas mediante qualquer uma das modalidades de pessoa jurídica previstas pela Lei $n^{\circ} 1551$, de 20 de abril de 1997, ou outras estabelecidas na legislação nacional, terão prioridade para a outorga de concessões florestais em terras fiscais de produção florestal permanente.

Na legislação brasileira o assunto da gestão das unidades de conservação foi tratado na Lei $\mathrm{n}^{\circ}$. 9.985/2000 (Sistema Nacional de Unidades de Conservação). Os artigos 23 a 36 da citada lei estabelecem normas gerais para a gestão das Unidades de Conservação.

Outra alternativa a se considerar para a gestão das unidades de conservação é a criação de conselhos gestores. Nesse sentido, o Estado do Rio de Janeiro já se manifestou legislativamente sobre a criação deste instrumento para as Unidades de Conservação no Estado, assim como os Estados do Acre e Rondônia em Reservas Extrativista.

O diploma que regulamenta tal conselho é a Lei Estadual $n^{\circ}$. 3443/2000. Outro aspecto importante a se considerar na gestão das unidades de conservação é o respeito às populações tradicionais que vivem nessas áreas. Neste aspecto a Lei $n^{\circ}$. 2393/1995 dispõe sobre a permanência de populações nativas residentes em unidades de conservação do Estado do Rio de Janeiro.

No que se refere ao trânsito de informações das, e para as, unidades de conservação a legislação norte-americana pode ser tida como referencial. Segundo ela, no caso do Sistema Nacional de Floresta do País, deve haver um fluxo das informações em três níveis administrativos: nacional, regional e local. Este princípio é importante não só para o fluxo de informações dos instrumentos da política florestal e ambiental dos estados, mas essencialmente para a criação de um sistema de gestão integrada.

Ainda no referido ato legislativo norteamericano observa-se um referencial para a formulação de um mecanismo de avaliação dos recursos renováveis. Dentre as determinações da lei norte-americana está a avaliação da oferta e demanda dos recursos naturais renováveis, assim como inventários e análises de custo de investimento. Esta determinação é de suma importância, uma vez que o uso sustentável das florestas só é possível por meio da constante avaliação dos recursos utilizados, principalmente no que diz respeito à demanda de 
produtos.

O Artigo $2^{\circ}$ da Lei $n^{\circ} 9.985 / 2000$ (SNUC) fornece a definição de Plano de Manejo como: "documento técnico mediante o qual, com fundamento nos objetivos gerais de uma unidade de conservação, se estabelece o seu zoneamento e as normas que devem presidir o uso da área e o manejo dos recursos naturais, inclusive a implantação das estruturas físicas necessárias à gestão da unidade". De acordo com esse diploma, todas as unidades devem possuir um Plano de Manejo. O artigo 27 fornece as diretrizes e princípios básicos para a elaboração de tais planos.

Como instrumento da autossustentabilidade econômica, a lei do SNUC prevê no artigo $5^{\circ}$ que a exploração comercial de qualquer produto elaborado a partir de recursos das unidades de conservação, inclusive os cênicos, dependerá de prévia autorização, além de sujeitar o explorador a pagamento, conforme regulamento.

Um aspecto importante no desenvolvimento sustentável das unidades de conservação de uso direto é o desenvolvimento econômico das zonas de amortecimento. Nessa matéria, importante contribuição é prestada por Putney (2000), segundo o qual: "muitos projetos internacionais que apoiam as unidades de conservação incluem atividades para fomentar o desenvolvimento sustentável das zonas de amortecimento". Estes são, em geral, projetos de desenvolvimento rural em pequena escala, utilizando-se de um enfoque participativo e adaptativo.

Os projetos que conseguiram aumentar o apoio das comunidades locais são os que empregam táticas para o desenvolvimento da política da boa vizinhança. Neste enfoque, a administração da unidade de conservação não se faz responsável pelo desenvolvimento sustentável da zona de amortecimento, mas acompanha as comunidades em sua busca por soluções por meio de outros atores sociais como as entidades estatais de desenvolvimento rural, universidades, organizações não governamentais e igrejas.

Pelo fato de serem localizados em uma zona de amortecimento, estes projetos devem obedecer ao requisito de que o seu impacto sobre as unidades de conservação seja pelo menos neutro. O projeto deve reduzir substancialmente os impactos negativos das comunidades sobre a unidade vizinha.

A Lei $n^{\circ} 22.723 / 38$ da província de Buenos Aires, na Argentina, tem por objetivo a proteção, a conservação, o melhoramento e a restauração dos recursos naturais e do ambiente em geral. A lei prevê em seu capítulo VI a existência do Fundo de Fomento de Parques Nacionais. Segundo o artigo 25 da referida lei, tal fundo se integra da arrecadação almejada com a venda, arrendamento e concessão de imóveis, instalações e bens móveis; com o produzido dos aforos e venda de madeira fiscal e outros frutos alcançados; com os direitos de caça e pesca; com os direitos de entradas e patentes; com os direitos de edificação, construções em geral, contribuições de melhoria, assim como com as taxas que se estabeleçam como retribuição de serviços públicos (MERCOSUL, 1998).

O montante arrecadado no referido fundo deve ser aplicado para a criação de Parques, Monumentos Naturais e Reservas Naturais; para a aquisição de bens necessários para o cumprimento das finalidades da lei; para a promoção de atividades que concorram para assegurar a melhor difusão e conhecimento das unidades de conservação, tais como a realização de congressos, exposições, mostras, campanhas de publicidade e outras que contribuam para a finalidade indicada; para a realização de cursos, estudos e pesquisas; os gastos com pessoal, gastos gerais e investimentos que demande o funcionamento da administração de Parques Nacionais. Pode ainda ser destinado ao cumprimento de outro departamento que deva realizar a administração dos parques nacionais, de acordo com as funções e atribuições que lhe sejam conferidas.

Encontra-se na Lei no 1.700/1996 da Bolívia importante referencial no que tange aos objetivos do desenvolvimento sustentável. No artigo $2^{\circ}$ desta lei são citados os ditos objetivos, que são:

a) estabelecer e fomentar as atividades florestais sustentáveis que contribuam para o desenvolvimento socioeconômico da nação;

b) promover o desenvolvimento sustentável dos recursos florestais e garantir a conservação dos ecossistemas, da biodiversidade e do meio ambiente;

c) proteger e recuperar as bacias hidrográficas, prevenir e deter a erosão das terras e a degradação das florestas, pradarias, solos e águas, e promover o reflorestamento;

d) facilitar a toda a população o acesso aos recursos florestais e seus benefícios, em estrito cumprimento das prescrições de proteção e sustentabilidade; promover a pesquisa florestal, assim como a sua difusão ao serviço dos processos produtivos, de conservação e proteção dos recursos florestais; 
e) fomentar o conhecimento e promover a formação de consciência da população nacional sobre o manejo responsável das bacias e seus recursos florestais (MERCOSUL, 1998).

Em algumas leis florestais da América Latina está prevista a existência do fundo florestal, a exemplo da Argentina, do Uruguai e do Chile (MERCOSUL, 1998). No Brasil tal fundo estava previsto no Decreto ${ }^{\circ}$. 23.793/ 1934, o qual foi revogado pela Lei $n^{\circ} .4 .771$ de 1965.

O Título III do livro V da Lei Florestal Francesa institui o Fundo Florestal Nacional Francês e seus objetivos e dispõe que "em vista da reconstituição das florestas francesas, o ministro das florestas assegura, de acordo com as modalidades fixadas pelos decretos, a organização de atividades de florestamento e reflorestamento, a avaliação e conservação dos terrenos florestados, a melhor utilização dos produtos da floresta e, em geral, tudo que tem por objetivo incrementar os recursos florestais, de facilitar a saída de produtos florestais e melhor satisfazer as necessidades das populações." (SANTOS, 1997).

\section{Perfil das unidades de conservação no Paraná e na Floresta Ombrófila Mista}

De acordo com dados fornecidos pelo Instituto Ambiental do Paraná (IAP), o Estado possui, em 2008, 64 unidades de conservação de domínio estadual, 13 de domínio federal, 110 de domínio municipal e 208 de domínio privado. Do total das unidades de conservação, $64 \%$ está incluído na categoria de unidades de conservação de proteção integral e $36 \%$ em unidades de uso sustentável (IAP, 2008; ICMBIO, 2008).

As unidades de conservação federais perfazem um total de 686.814 ha, sendo que apenas 72.405 ha $(10,54 \%)$ estão na região do Bioma Florestal com Araucária.

As unidades de conservação estaduais, por outro lado, têm uma área total de 1.195.370 ha, distribuídos por todo o Estado. Deste total, $974.982,34$ ha $(81,56 \%)$ estão incluídos no Bioma de Araucária. Cerca de 50.922,2 ha (5,23 \%) pertencem à categoria das UCs de proteção integral e 924.060,14 ha $(94,77 \%)$ pertencem à categoria de uso sustentável (IAP, 2008).

O grande problema, porém, dessas unidades reside na dificuldade estrutural e de recursos que o Estado encontra na gestão desses espaços, a exemplo do Parque Estadual de Vila Velha, que por anos ficou praticamente entregue à própria sorte.
Finalmente, merece destaque, no Estado do Paraná, a proliferação das RPPNs, que de acordo com dados do IAP hoje somam 208 unidades. Deste total, cerca de $72,2 \%$ estão inserido no Bioma Florestal com Araucária, sendo que hoje as RPPNs estaduais ocupam uma área de 41.703 ha (IAP, 2008). Grande obstáculo surge à medida que o Poder Público não fornece as condições estruturais mínimas, nem exerce sobre estes locais a vigilância efetiva para que se alcance o objetivo esperado, que é a manutenção dos remanescentes florestais em áreas particulares.

\section{MATERIAIS E MÉTODOS}

O trabalho busca, através de experiências estrangeiras já realizadas e que agora servem como alicerce para o desenvolvimento da pesquisa, subsídios para arquitetar uma estratégia ambiental para a preservação dos remanescentes do Bioma Florestal com Araucária.

As unidades de conservação de proteção integral assumirão importante função, consideradas, porém, todas as limitações legais inerentes à categoria, sem perder em importância para a outra categoria, mas funcionando de forma complementar e análoga.

Num primeiro momento destaca-se a função de proteção da biodiversidade e da manutenção do ecossistema integral e incólume, que deverá abrigar essencialmente matrizes genéticas, porta-sementes, como uma forma de reverter o processo de erosão genética da Araucária e, fundamentalmente, permanecer como testemunho cultural, histórico e científico do Bioma Florestal com Araucária. Ressalta-se também a incumbência de melhoria da qualidade paisagística local.

Ainda, dentro das limitações de uso, esses espaços devem ser destinados ao desenvolvimento de atividades de educação ambiental, turismo ecológico e científico. Finalmente, essas áreas deverão estar formando os elos entre as unidades de conservação, criando os desejáveis corredores ecológicos dentro do Bioma.

\section{Estratégias para unidades de uso sustentável}

De acordo com dados do Instituto Ambiental do Paraná, o Estado possui 1.299 ha ocupados por florestas estaduais, 519,9 ha com reservas florestais e 4.223 ha com florestas nacionais. A superfície do Estado transformada em unidades de Reservas Particulares do Patrimônio Natural é crescente de 
49.458 ha (IAP, 2008). Extensão, porém, que nem sequer se aproxima da superfície ocupada por Áreas de Proteção Ambiental, que se distribuem por mais de 11.589.138 ha do Bioma.

Ações meramente repressivas e estratégias coercitivas têm se mostrado insuficientes para manter os remanescentes florestais no País, que vêm paulatinamente perdendo sua cobertura florestal. O grande desafio está em criar estratégias que conciliem a conservação e preservação ambiental ao desenvolvimento econômico e social. Medidas isoladas também apresentam deficiências. Alternativa viável para manter os remanescentes florestais, sem onerar sobremaneira a população residente no Bioma, está na criação de planos de desenvolvimento das unidades de conservação de uso sustentável. Para tanto, criou-se um conjunto de medidas aplicáveis às categorias de unidade de conservação existentes e a serem criadas no Bioma Florestal com Araucária no Paraná.

Dentro de uma perspectiva de uso dos recursos sustentáveis, o que se pretende a partir deste ponto é a proposição de uma regulamentação do aproveitamento dos recursos naturais em espaços naturais protegidos. Para tanto, foram selecionadas e trabalhadas duas categorias de UCs, já existentes, em relação a sua gestão e possibilidade de uso dos produtos da floresta, e proposta a criação de uma nova modalidade, dentro de uma concepção de desenvolvimento sustentável. Foram desenvolvidas estratégias diferenciadas, aplicáveis às diferentes situações, mas com fulcro no desenvolvimento sustentável das florestas com Araucária.

\section{RESULTADOS E DISCUSSÃO}

\section{Reserva Particular do Patrimônio Natural (RPPN)}

Dentre as modalidades de UC esta se sobressaiu no Paraná com um aumento numérico significativo, com mais de quinhentas propriedades rurais averbadas nos últimos anos. Contudo, alguns aspectos merecem ser discutidos.

O primeiro diz respeito à carência de recursos estruturais e monetários destinados à manutenção e gestão destas áreas, eis que, por vezes, quem recebe compensação financeira em função da existência deste espaço protegido é o Poder Público, como é o caso do valor decorrente do ICMS ecológico no Paraná, restando ao particular o ônus da restrição de uso da propriedade, da tutela e vigilância da floresta.

Na resolução do problema algumas medidas podem ser tomadas. A primeira alternativa é a criação de uma linha de financiamento exclusiva para a promoção do ecoturismo em reservas particulares. Em tempo, outra alternativa, polêmica, mas viável, é o incentivo à exploração de baixo impacto de recursos não madeireiros oriundos destas propriedades, apesar da vedação legislativa, decorrente do artigo 21, 220 , do SNUC, que pode e deve ser alterado.

No caso específico do Bioma Florestal com Araucária, o foco deve estar centrado no aproveitamento de plantas medicinais e de outros subprodutos não madeireiros. Objetivando o controle e a promoção destes produtos, é interessante a criação de um certificado de origem, que possa estar sob a responsabilidade do Estado ou mesmo de organizações não governamentais, com a fiscalização do Estado.

\section{Florestas Estaduais}

O Sistema Nacional de Unidades de Conservação dispõe que as Florestas Nacional, Estadual e Municipal são áreas florestais contínuas, que devem possuir espécies predominantemente nativas. Estas áreas são, obrigatoriamente, de posse e domínio públicos, sendo que o Poder Público deverá desapropriar as áreas necessárias à sua criação. Importante destacar que esta modalidade tem como objetivo o uso múltiplo e a conservação dos recursos florestais renováveis e a pesquisa científica.

Hoje, de acordo com dados fornecidos pelo Instituto Ambiental do Paraná (Tabela 1), o Estado possui pequena extensão do território protegido por esta ferramenta (cerca de 769 ha) deixando de usufruir este poderoso instituto na preservação do Bioma Florestal com Araucária. Advoga-se nesta tese que as florestas estaduais no Paraná podem ter valioso papel não apenas na preservação do meio ambiente, mas também na regulação dos estoques de madeira de Araucária e outras essências de valor comercial, e, por via transversa, para o desenvolvimento social e econômico regional.

Porém, para que sejam exploradas, é necessário que as Florestas Estaduais disponham de um plano de manejo, uso e conservação, por meio do qual sejam definidos os objetivos específicos da unidade, seu zoneamento e sua utilização. O uso sustentável das Florestas Estaduais deve ter como objetivo primeiro a manutenção do equilíbrio ambiental, associado ao desenvolvimento social e econômico regional. 
Essas unidades são constituídas em propriedades do Estado e destinam-se a assegurar, mediante exploração racional, um suprimento de produtos florestais e a proteger a fauna e a flora locais, de modo a garantir a sobrevivência de suas espécies em condições naturais. Esta exploração poderá ser feita diretamente pelo Poder Público ou por meio de contratos com particulares, reservado para o Estado o domínio da terra, podendo ser outorgadas concessões, a pessoas físicas ou jurídicas, para o desenvolvimento de atividades silviculturais.

Os contratos para a exploração das Florestas Estaduais poderão ser feitos mediante processo licitatório na modalidade de concorrência pública, ficando estabelecido que, no instrumento convocatório, deverá constar de forma clara, como um dos critérios de julgamento da proposta, a capacidade de desdobro secundário na forma de beneficiamento mínimo, dentro dos limites territoriais do município, visando ao desenvolvimento daquela população diretamente afetada pelo empreendimento.

Os recursos financeiros provenientes das concessões serão destinados à Conta Especial Para a Gestão das Unidades de Conservação de Uso Sustentável, a ser tratado mais adiante.

No contrato de concessão, o concessionário se obrigará a cumprir as Leis Florestais e Ambientais do Estado, bem como as disposições do Plano de Manejo da respectiva unidade. Caso o concessionário não cumpra a legislação, ou viole normas específicas ou cláusulas contratuais, terá o contrato de concessão rescindido.

O Plano de Manejo deverá sofrer revisão periódica a cada dois anos pelo órgão competente. No resguardo do interesse público, é crucial o estabelecimento pelo Estado de garantia da prestação das atividades previstas em contrato, no instrumento convocatório do processo licitatório, podendo o contratante optar por uma das seguintes modalidades de garantia:

I - caução em dinheiro ou bens imóveis;

II - seguro-garantia;

III - fiança bancária.

O Governo, através de seus órgãos especializados, fará um inventário florestal, estimando a qualidade e a quantidade de recursos disponíveis em cada unidade de conservação, sendo que a realização do inventário florestal deverá, obrigatoriamente, anteceder ao processo licitatório de concessão para exploração dos recursos florestais.
Finalmente, dois pontos fundamentais precisam ser ressaltados. O primeiro é que em cada Unidade de Conservação a soma de todas as concessões não poderá exceder a $25 \%$ (vinte e cinco por cento) da área total da mesma. Em cada Floresta Estadual de mata natural será reservada uma ou mais áreas a serem mantidas intocáveis, as quais deverão constituir amostra expressiva dos recursos naturais do local.

Ora, é certo que se assume um risco em relação ao remanescente, que pode ser sanado pela ação eficaz do Poder de Polícia do Estado, mas é certo também que não se pode sacrificar toda uma região, que, por vezes, está sentada sobre precioso recurso, e hoje está sendo estigmatizada por ter conservado suas florestas sob a justificativa de que a Araucária precisa ser preservada, a qualquer custo.

\section{Reservas Particulares de Desenvolvimento Sustentável (RPDS)}

Proposta para a criação de uma nova categoria de unidade de conservação

Concepção técnica e normativa das Reservas Particulares de Desenvolvimento Sustentável (RPDS)

A Reserva Particular de Desenvolvimento Sustentável (RPDS) será uma nova categoria de unidade de conservação, constituída em áreas com cobertura florestal com espécies predominantemente nativas, dotada de atributos ecológicos importantes, que tem como objetivo básico o uso múltiplo sustentável dos recursos florestais, madeireiros e não madeireiros, o desenvolvimento socioeconômico regional e a pesquisa científica, com ênfase em métodos para exploração sustentável da floresta.

A RPDS é de posse e domínio privados, gravada com perpetuidade, e com uso condicionado às normas estabelecidas para o manejo da unidade pelo órgão responsável por sua fiscalização. A RPDS assemelha-se ao instituto da Reserva de Desenvolvimento Sustentável (art. 20 do SNUC), que está sob o domínio público, estando, porém, esta sob a tutela do particular.

Nessas áreas é admitida a permanência do proprietário e de seus familiares que ali residiam quando da sua criação, respeitados os limites dispostos no plano de manejo da unidade.

Será incentivado nessa área o uso múltiplo da floresta mediante a exploração da madeira, de produtos não madeireiros e do ecoturismo, atividades estas sujeitas às normas estabelecidas no plano de manejo. 
A exploração madeireira só será permitida em bases sustentáveis, com o uso de técnicas de baixo impacto, e acompanhada de outras atividades que deverão ser desenvolvidas no local. A exploração dependerá da aprovação do plano de manejo florestal, seguindo rígido regramento e sob constante vigilância do órgão gestor.

Estão proibidas nesse local a exploração mineral, a caça amadorística ou profissional.

Será incentivado o desenvolvimento de projetos científicos voltados à conservação da natureza, sujeitos à aprovação do órgão ambiental responsável, sendo desejável a consulta ao conselho consultivo da UC.

Fica estabelecido que no mínimo $25 \%$ da área com cobertura florestal deverá ser mantida intocada na propriedade. Ainda que, parte dos recursos obtidos com a exploração dos recursos naturais deverá ser destinada à Conta Especial para a Gestão das Unidades de Conservação, a ser tratado posteriormente.

Essas áreas disporão de um Conselho Deliberativo presidido pelo órgão responsável pela sua administração e constituído por representantes dos órgãos públicos, dos proprietários das RPDS e das organizações da sociedade civil. Este conselho terá a função principal de traçar as diretrizes para o uso racional destas áreas protegidas no Estado, resguardadas as disposições legais e o direito de propriedade, garantido constitucionalmente.

A comercialização dos produtos e subprodutos resultantes da exploração estará vinculada à certificação do produto pelo órgão competente.

Diante do exposto, é possível apontar uma série de vantagens auferidas pelo proprietário e pela sociedade na criação e preservação dessas áreas.

$\mathrm{O}$ primeiro ponto positivo ocorre com a manutenção da biodiversidade local, pela preservação de remanescente da floresta, que, mesmo que tenha parte do seu todo explorada, terá uma área mínima de $25 \%$ do total integralmente preservada, como sugerido na criação do instituto. Importante destacar que estas áreas deverão ser obrigatoriamente averbadas. Esta averbação tem caráter de perpetuidade, barrando qualquer tentativa de alteração de uso do solo no momento presente ou futuro.

Uma segunda vantagem resulta da exploração florestal que terá parte do montante destinado à Conta Especial que será reservado para a gestão e manutenção do sistema de unidades de conservação no Estado.

O terceiro aspecto positivo dar-se-á pela melhoria da qualidade de vida da população residente no entorno, pelo aumento da oferta regional de empregos e criação de uma consciência ecológica da população, que estará aprendendo a valorizar o recurso ambiental disponível.

O proprietário rural terá seu interesse despertado para aderir ao programa, pois o Estado deverá fomentar a venda dos produtos certificados oriundos destas áreas. Estes produtos, consequentemente, poderão ter um incremento no volume comercializado do produto, em razão da propaganda de um artigo produzido de forma ecologicamente correta.

Ainda, vale salientar que prioridade deverá ser dada ao desenvolvimento de programas de formação profissional, para membros provenientes das comunidades locais, que deverão estar fazendo o beneficiamento dos produtos de madeira.

Por fim, interessa ao produtor rural instituir esta unidade de conservação em sua propriedade, porque, apesar de ter o uso da terra limitado, usufruirá um conjunto de benefícios fiscais, exclusivos para as Reservas Particulares de Desenvolvimento Sustentável, como a isenção do Imposto Territorial Rural e a aplicação de alíquota diferenciada na aplicação do Imposto sobre Transferência de Bens Imóveis.

\section{Limitação à Exploração Florestal nas Unidades de Conservação de Uso Sustentável Limitação principiológica}

Apesar da farta legislação nacional referente à proteção do meio ambiente, poucas são as normas jurídicas que contemplam o uso dos recursos florestais nas unidades de conservação. $\mathrm{O}$ estudo destas normas, no entanto, é válido, porque a análise da legislação nacional, estadual e municipal oferece grandiosos auxílios à real satisfação dos interesses da coletividade, objetivo maior do ordenamento jurídico.

Observam-se, porém, limitações genéricas em relação à preservação das florestas e das unidades de conservação, estabelecidas, principalmente, pela Constituição Federal, Declaração de Estocolmo, Declaração do Rio de Janeiro (Rio 92), Lei de Crimes Ambientais, Lei do SNUC, Política Nacional do Meio Ambiente e o Código Florestal.

Tais diplomas estabelecem princípios e delegam atribuições aos entes federativos no que concerne à proteção, preservação e restauração 
do ambiente, garantindo a qualidade de vida da população. Os princípios de direito ambiental vinculam a produção e a aplicação das leis em todos os seus níveis, atuam como verdadeira regra jurídica. E mais, são parâmetros utilizados na aplicação da norma ao caso concreto, formadores do regime jurídico ambiental.

Ressalta-se, porém, a necessidade de limitações específicas ao uso econômico das unidades de conservação. A direção a ser tomada deve compatibilizar os interesses econômicos com os interesses ambientais, ou seja, o uso ecoeconômico dos recursos florestais, garantindo a sustentabilidade da floresta em benefício da vida humana.

Nesse sentido, Mukai (2002) assevera que "a Constituição Federal Brasileira, ao contemplar no mesmo plano (art. 170, IV e VI) os princípios da livre concorrência e o da defesa do meio ambiente, não admite que este último seja colocado de lado com privilégio do primeiro". O autor continua afirmando que "há que se compatibilizar, sempre e a todo custo os dois princípios. E, em caso de conflito real, há que se efetuar uma ponderação de interesses, para que não haja sacrifício total de um ou de outro. Importante assinalar a necessidade de tratamento jurídico diferenciado às diferentes modalidades de unidades de conservação tendo em vista suas finalidades, principalmente no que diz respeito à função social de cada uma delas".

As unidades de conservação de uso direto deverão ser exploradas de forma racional respeitando os limites de sustentabilidade de cada localidade.

Os recursos obtidos através das atividades desenvolvidas nas unidades de conservação deverão ser direcionados à preservação e recuperação das Florestas de Araucária e ao desenvolvimento social e econômico da região onde está inserida a floresta. As modalidades Floresta Estadual, RPPN e RPDS deverão ter usos distintos, levando em consideração as especificidades e finalidades de cada uma.

Deverá ser criado um sistema especial de fiscalização e controle das áreas de interesse, preferencialmente utilizando os recursos obtidos com a atividade de exploração, destinados especificamente para as unidades de conservação de uso direto.

As atividades de exploração dos recursos naturais das áreas protegidas deverão, preferencialmente, ser explorados pelas comunidades locais.

\section{Limitação à Concessão}

$\mathrm{Na}$ esfera administrativa a atuação do Estado, na garantia dos direitos coletivos, perfaz-se principalmente com a realização de procedimentos licitatórios, a fim de conceder o uso de espaços florestais àquele que melhor corresponda aos anseios sociais e ecológicos. Sendo assim, a análise das Leis $n^{\circ}$. 8.666/93 (Lei de Licitações) e $n^{\circ}$. 8.987/95 (Lei do Regime de Concessão e Permissão) são imprescindíveis à definição de parâmetros para elaboração do procedimento licitatório e do contrato de concessão para atividades florestais. Os princípios contidos nestas normas são aplicáveis aos contratos que têm como objeto a exploração de uma unidade de conservação, mas sempre em consonância com os princípios de direito ambiental.

A relevância ambiental e econômica da contemporaneidade em relação à atividade exploratória dos recursos florestais conduz à construção de ferramentas essenciais à proteção dos interesses coletivos ainda no procedimento licitatório. Por esta razão, deve ser estabelecida a prestação de garantia acessória ao contrato de concessão para a exploração dos recursos florestais e o desdobro mínimo dos recursos florestais, como forma de agregar valor maior nas atividades mercantis ainda no Estado em que as unidades estão localizadas.

\section{Limitações Estabelecidas ao Uso dos Recursos Florestais nas Unidades de Conservação de Uso sustentável}

O Plano de Manejo Florestal é um instrumento hábil para garantir a viabilidade econômica do projeto de exploração a ser realizado. Além disso, deverá garantir o mínimo impacto sobre o meio ambiente, prevendo inclusive a reserva de espécies florestais e a proteção dos abrigos dos animais locais.

A exploração deverá ser progressiva em relação aos parâmetros, visando atingir um grau de uso semelhante à capacidade de regeneração anual das Florestas de Araucária, que de acordo com Sanquetta et al. (2001), é de aproximadamente 40 anos. A proporção estabelecida aproxima os parâmetros exploração e capacidade de regeneração conforme a área total da unidade. O crescimento das árvores é um processo ecológico dinâmico quando, em geral, as espécies pioneiras crescem mais rapidamente que as espécies clímax, e a mistura de floras é algo que pode mascarar evidências aparentes de declínio de comunidades florestais 
(WHITMORE, 1990; FINEGAN, 1984). Porém, a criação de unidades de grandes dimensões e de formato regular possibilita uma maior equivalência entre a exploração e a regeneração florestal.

A proporção ideal de exploração deveria estar restrita a $2,5 \%$ da área total ao ano, o que possibilitaria a regeneração total da área em 40 (quarenta) anos, quando poderia ser novamente explorada. No entanto, a restrição supra acabaria por impossibilitar a exploração em áreas pequenas. Para viabilizar a atividade produtiva, prestigiando os pequenos e médios proprietários rurais, foram criados valores intermediários de exploração para áreas inferiores a 300 ha e para áreas entre 300 ha e 1.000 ha. A área anual passível de exploração é formada por um conjunto de cálculos mantendo a equivalência para exploração nos três grupos (Tabela 1).

O grupo I abrange áreas inferiores a 300 ha, permitindo a exploração anual de até $10 \%$ da área total da unidade.

No grupo II, contendo unidades com área superior a 300 ha e inferior a 1.000 ha, tem-se a limitação correspondente à soma de 30 ha, mais a soma do resultado da multiplicação de $4 \%$ e a diferença entre a área total e 300 ha. A limitação assim exposta procura manter a equivalência da viabilidade produtiva entre os grupos (na ausência de estudos econômicos específicos, parte-se do pressuposto de que os limites de área permitem uma exploração econômica sustentável nas três áreas). Os 30 ha base são resultantes da análise dos primeiros 300 ha da área da unidade à limitação de $10 \%$ para exploração. A exploração limitada a $4 \%$ atinge o montante da área total da unidade reduzido de 300 ha, estes inclusos na exploração base ( 30 ha), evitando-se, assim, considerar duas vezes a mesma área como parâmetro para exploração.

A representação constante no grupo III segue a mesma linha aplicada ao grupo II. A limitação dá-se pela soma de 58 ha adicionada de $2,5 \%$ da diferença entre a área total e 1.000 ha. Primeiro, o quantum base de 58 ha é resultado da aplicação da limitação de $10 \%$ de exploração aos primeiros 300 ha e da aplicação do limitador de $4 \%$ à área superior a 1.000 ha e inferior a 300 ha. No primeiro caso, resultando em 30 ha e no segundo em 28 ha, totalizando 58 ha base passíveis de exploração. A limitação de $2,5 \%$ atinge a área total da unidade reduzida de 1.000 ha, pois estes já foram analisados e calculados, formando a exploração base. Mais uma vez, evita-se a utilização dúplice do parâmetro, a fim de calcular a área passível de exploração. Isto posto, nota-se que é mantida a equivalência quanto à viabilidade econômica dos diversos grupos. E mais, demonstra-se uma tendência à correspondência entre a capacidade de regeneração da floresta e a área passível de exploração anual dada pela dimensão total da unidade.

A Tabela 2 mostra como seria a adoção de princípios para a criação de novas unidades de conservação. Esses princípios se baseiam na criação de unidades extensas e de formato regular, a fim de preservar o meio ambiente, procurando não inviabilizar economicamente o empreendimento, e com isso, compatibilizar o fator de capacidade de regeneração da floresta e a sua exploração. Pressupõe-se aqui que, da área total, apenas um determinado percentual é passível de exploração a cada ano. Esse procedimento permite que, ao final de $\mathrm{n}$ anos, um novo ciclo se inicie com a exploração da área utilizada no primeiro ano. Esse conceito cíclico de exploração florestal visa atingir o máximo grau de capacidade de regeneração das áreas exploradas, facultando o ingresso de receitas anuais, mas mantendo a perenidade do recurso natural. Nesse sentido, este procedimento torna-se um consistente instrumento de sustentabilidade socioeconômica e ambiental. Destaca-se a importância de privilegiar a criação de unidades de conservação com maiores dimensões, visando possibilitar uma completa regeneração da floresta, concluído o ciclo estabelecido em estudos. Além disso, a criação de unidades de maiores dimensões protege o interesse coletivo e o meio ambiente, além de restringir o poder discricionário dos agentes políticos.

TABELA 1: Concepção simplificada do modelo proposto.

TABLE 1: Simplified conception of the proposed model.

\begin{tabular}{l|l|l}
\hline GRUPO I & Áreas $<300 \mathrm{ha}$ & $10 \% \mathrm{da}$ área total \\
\hline GRUPO II & Áreas $>300 \mathrm{e}<1.000 \mathrm{ha}$ & $30 \mathrm{ha}^{\mathrm{A}}+4 \% \mathrm{x}($ área total $-300 \mathrm{ha})$ \\
\hline GRUPO III & Áreas $>1.000 \mathrm{ha}$ & $58 \mathrm{ha}^{\mathrm{B}}+2,5 \% \mathrm{x}($ área total $-1.000 \mathrm{ha})$ \\
\hline
\end{tabular}

Em que: ${ }^{\mathrm{A}}=30$ ha correspondem à máxima exploração do GRUPO I; ${ }^{\mathrm{B}}=58$ ha correspondem à exploração máxima do GRUPO I + GRUPO II. 
TABELA 2: Simulação de uso dos recursos madeireiros nas unidades de conservação de uso sustentável.

TABLE 2: Timber resources simulation in conservation units of sustainable use.

\begin{tabular}{c|c|c|c}
\hline \multirow{2}{*}{$\begin{array}{c}\text { Categoria } \\
\text { Floresta Nacional } \\
\text { ou } \\
\text { Estadual }\end{array}$} & $\begin{array}{c}\text { Dimensão } \\
\text { (ha) }\end{array}$ & $\begin{array}{c}\text { Área explorável } \\
\text { (ha) }\end{array}$ & $\%$ \\
\cline { 2 - 4 } & 4,000 & 133,25 & 3,323 \\
\cline { 2 - 4 } & 3,200 & 113 & 3,531 \\
\cline { 2 - 4 } & 1,600 & 73 & 4,562 \\
\hline \multirow{4}{*}{ RPDS } & 1,030 & 58,75 & 5,704 \\
\cline { 2 - 4 } & 988 & 57,52 & 5,822 \\
\cline { 2 - 4 } & 879 & 53,16 & 6,048 \\
\hline \multirow{4}{*}{ RPPN } & 568 & 40,72 & 7,169 \\
& 318 & 30,76 & 9,661 \\
\cline { 2 - 4 } & 297 & 29,7 & 10 \\
\cline { 2 - 4 } & 245 & 24,5 & 10 \\
\hline
\end{tabular}

\section{Reestruturação administrativa}

\section{Conta especial para a gestão das unidades de conservação-CEGUC}

A Conta Especial para o Desenvolvimento das Unidades de Conservação de Uso Sustentável (CEGUC) foi criada como instrumento hábil para a autogestão das unidades de conservação. Há de se destacar a limitada capacidade do aparato estatal na fiscalização de suas extensas áreas verdes, daí a necessidade de implantação de um sistema próprio para o controle das atividades relacionadas a este objeto.

A eficácia de um instrumento legal é indissociável da reestruturação da fiscalização e gestão das atividades realizadas na unidade de conservação tendo em vista os fins a que se destina. Entende-se por reestruturação dos mecanismos de fiscalização sua descentralização, tornandoos mais efetivos e concentrados. A participação da sociedade e do terceiro setor é muito relevante neste aspecto, pois irá complementar a fiscalização estatal. Observa-se, neste aspecto, a importância da educação ambiental (Lei nº 9.795/99), destacandose a formação de uma consciência ambiental social, preservando e, indiretamente, fiscalizando o meio ambiente.

Não obstante, na situação acima especificada, nota-se a importância da criação de um sistema de gestão próprio para as unidades de conservação de uso sustentável. Um sistema de gestão evitaria o desvio de finalidade na aplicação dos recursos advindos do contrato para exploração das unidades, combatendo o uso arbitrário do Erário e restringindo moderadamente o poder discricionário do administrador público.

A criação de uma conta, formada pelo conjunto de receitas advindas da utilização econômica das unidades, estabeleceria um sistema de autogestão das unidades, dada pela aplicação dos recursos aos fins desejados (infraestrutura, fiscalização, desenvolvimento tecnológico, elaboração de planos de manejo, incentivos etc.), garantindo a independência e a estabilidade financeira do sistema.

Esse instrumento terá o objetivo de fomentar atividades que visem:

a) promover a melhoria da qualidade ambiental;

b) intensificar e aprimorar a fiscalização;

c) melhorar a infraestrutura e das vias de acesso nas UCs;

d) estimular iniciativas que possam beneficiar a população local;

e) promover a capacitação e educação ambiental para a comunidade do entorno das UCs;

Constituirão recursos da CEGUC:

a) recursos financeiros provenientes da concessão ou direito de uso das Florestas Estaduais e das Reservas Extrativistas;

b) recursos advindos de indenizações por descumprimento de previsões contratuais ou normas legais referentes às UCs;

c) recursos advindos pela aplicação de multas pela prática de atos ilícitos cometidos nas Unidades de Conservação de Uso Sustentável; 
d) rendimentos de qualquer natureza auferidos com a remuneração decorrente da aplicação de seu patrimônio;

e) dotações orçamentárias do Estado;

f) recursos resultantes de doações, contribuições em dinheiro, bens móveis e imóveis, de pessoas físicas ou jurídicas;

g) quaisquer outras rendas eventuais.

Os recursos provenientes dos contratos de concessão para a exploração das UCs deverão obrigatoriamente ser aplicados na CEGUC.

\section{Síntese da proposta de aproveitamento das unidades de conservação de uso sustentável}

O Brasil adotou em sua política ambiental a criação de Unidades de Conservação como meio de efetivação da proteção e desenvolvimento florestal (Lei $n^{\circ}$. 6.938/81). As Unidades de Conservação formam um microssistema de preservação ambiental, e a implantação de um Sistema Nacional de Unidades de Conservação (Lei n ${ }^{\circ}$. 9.985/2000) demonstra uma real possibilidade de integração entre desenvolvimento socioeconômico e preservação ambiental.

Destaca-se nesse contexto que, a Política Florestal é formada por um conjunto sistematizado e ordenado de atos, limitados por princípios gerais ambientais, objetivando um fim comum. Logo, a unidade de conservação como instrumento depende da realização dos instrumentos outros na esfera fática. E mais, embora os incentivos fiscais não possam ser conferidos senão por lei específica, não se descarta sua utilização como meio hábil à realização material da política florestal.

A legislação federal estabelece medidas jurídicas relevantes à proteção dos interesses difusos e coletivos, os quais Bobbio (1987) denomina de direitos de terceira geração, mas tais medidas são pouco eficazes no campo prático. Logo, a principal deficiência na efetivação da política florestal é a execução da previsão legal, a otimização da fiscalização e a vigilância das atividades práticas. Observa-se que esta deficiência legislativa não é própria do Estado nacional, dos estados e municípios brasileiros, mas atinge os países do MERCOSUL.

No entanto, a criação de uma norma executiva da política florestal que se refira às Unidades de Conservação deverá ser realizada pelos Estados (dentro dos limites de competência estabelecidos pela Constituição Federal), em virtude da especificidade dos Biomas no território brasileiro, fator esse que dificultaria a criação de uma norma nacional. A exploração modular, tendo por parâmetro a capacidade de regeneração da floresta, aparenta ser a mais efetiva forma de controle legal da degradação ambiental. A progressividade da área passível de exploração criaria uma equivalência entre unidades de dimensões variadas, garantindo a viabilidade econômica em todas as categorias.

Isto posto, deduz-se que, visando otimizar a política florestal, os Estados precisam normatizar a utilização econômica das Unidades de Conservação de Uso Sustentável, como sugerido na Tabela 3. A norma poderá garantir a sustentabilidade de uma floresta de acordo com a capacidade de regeneração, imprescindível para finalização de estudos técnicocientíficos de longa duração.

\section{CONCLUSÕES}

A legislação florestal vigente e pretérita, do ponto de vista técnico e legislativo, mostrase consistente. No entanto, registram-se algumas distorções legais recentes, mais especificamente com a edição de normas pelo Poder Executivo, que extrapola sua capacidade normativa e dificulta o exercício da atividade silvicultural, bem como o desenvolvimento socioeconômico no Bioma.

TABELA 3: Proposta de aproveitamento das unidades de conservação de uso sustentável.

TABLE 3: Proposal for usage of conservation units of sustainable use.

\begin{tabular}{l|c|c|c|c|c}
\hline \multicolumn{1}{c|}{ ATIVIDADES/MODALIDADES } & APA & ARIE & FLOE & RPPN & RPDS \\
\hline Exploração de erva-mate & $\operatorname{sim}$ & $\operatorname{sim}$ & $\operatorname{sim}$ & $\operatorname{sim}$ & $\operatorname{sim}$ \\
\hline Exploração do pinhão & $\operatorname{sim}$ & $\operatorname{sim}$ & $\operatorname{sim}$ & $\operatorname{sim}$ & $\operatorname{sim}$ \\
\hline Exploração de plantas medicinais & $\operatorname{sim}$ & $\operatorname{sim}$ & $\operatorname{sim}$ & $\operatorname{sim}$ & $\operatorname{sim}$ \\
\hline Resinagem & não & não & $\operatorname{sim}$ & não & $\operatorname{sim}$ \\
\hline Ecoturismo & $\operatorname{sim}$ & $\operatorname{sim}$ & $\operatorname{sim}$ & $\operatorname{sim}$ & $\operatorname{sim}$ \\
\hline Exploração madeireira & não & não & $\operatorname{sim}$ & não & $\operatorname{sim}$ \\
\hline
\end{tabular}


O Sistema Estadual de Unidades de Conservação é uma importante ferramenta para a preservação dos remanescentes de Floresta de Araucária no Paraná, mas ainda vem sendo usado de forma desequilibrada, em relação às categorias de Unidades de Proteção Integral e Unidades de Uso Sustentável. As Unidades de Proteção Integral têm desempenhado papel expressivo na preservação do Bioma Florestal com Araucária, experimentando um acentuado crescimento quantitativo no Paraná. Em contrapartida, as Unidades de Conservação de Uso Sustentável são inexpressivas no Bioma e necessitam de uma efetiva regulamentação para que desempenhem sua função ecológica e social.

Medidas de incentivo à conservação das florestas particulares e ao uso sustentável dos recursos madeireiros e não madeireiros, somadas ao instrumental atualmente utilizado, podem contribuir com maior efetividade na conservação e recuperação do Bioma Florestal com Araucária.

\section{REFERÊNCIAS BIBLIOGRÁFICAS}

BAQUERIZO, C. A. Derecho Ambiental: Manual Práctico. Madrid: Penthalon, 1990. $114 \mathrm{p}$.

BÉLGICA. Decreto $n^{\circ} 16 / 07 / 85$. Decreto relativo aos Parques Naturais, 1985.

BOBBIO, N. Teoria General del Derecho. Bogotá: Temis, 1987.

BRASIL. Conselho Nacional de Meio Ambiente. Resolução n. 11, de 03 de dezembro de 1987. Diário Oficial da República Federativa do Brasil, Brasília, DF, 18 de março de 1988. Seção 1, p. 4563. BRASIL. Lei n . 9.985, de 18 de julho de 2000. Regulamenta o art. 225, $\S 1^{\circ}$, incs. I, II, III, e VII da Constituição Federal, institui o Sistema Nacional de Unidades de Conservação da natureza e dá outras providências. Legislação Ambiental Federal. Curitiba: Juruá, 2002.

BRASIL. Lei n. 4.771, de 15 de setembro de 1965. Institui o Novo Código Florestal. Legislação Ambiental Federal. Curitiba: Juruá, 2002.

BRASIL. Lei n. 8.987, de 13 de fevereiro de 1995. Dispõe sobre o regime de concessão e permissão da prestação de serviços públicos previsto no art. 175 da Constituição Federal, e dá outras providências.

BRASIL. Lei n. 8666, de 21 de junho de 1993. Regulamenta o art. 37, inciso XXI, da Constituição Federal, institui normas para licitações e contratos da Administração Pública e dá outras providências. BRASIL. Lei n. 9795, de 27 de abril de 1999. Dispõe sobre a educação ambiental, institui a
Política Nacional de Educação Ambiental e dá outras providências. Diário oficial da república Federativa do Brasil, 28 de abril de 1999.

Diário oficial da república Federativa do Brasil, 14 de fevereiro de 1995.

Diário Oficial da República Federativa do Brasil, 22 de junho de 1933.

ENCUENTRO NACIONAL DE DERECHO FORESTAL AMBIENTAL, 2006, Lima. Memória del Encuentro Nacional de Derecho Forestal Ambiental. Lima: Derecho Ambiente y Recursos Naturales, 2006.

ESPAÑA. Legislación forestal. 4. ed. Madrid: Editorial Tecnos, 2001. $661 \mathrm{p}$.

FINEGAN, B. Forest succession. Nature, 1984. v. 312, p. 109-114.

FRANÇA - Lei n. 76-629, de 10 de julho de 1976. Relativa a proteção da natureza, 1976.

IAP - Instituto Ambiental do Paraná. Disponível em: <(http://www.uc.pr.gov.br/)> Acesso em: 25/08/2008.

ICMBIO - Instituto Chico Mendes de Conservação da Biodiversidade. Disponível em: < (http://www. icmbio.gov.br)> Acesso em: 25/08/2008.

MAACK, R.. Geografia física do Estado do Paraná. Curitiba: CODEPAR, 1968. 350 p.

MUKAI, T. Direito Ambiental Sistematizado. 3. ed. São Paulo: Forense Universitária, 2002. 186 p.

PUTNEY, C. Rede Nacional Pró-Unidades de Conservação: Fundação O Boticário de Proteção à Natureza. In: I Congresso Brasileiro de Unidades de Conservação, Campo Grande. In: CONGRESSO BRASILEIRO DE UNIDADES DE CONSERVAÇÃO, 1., 2000, Campo Grande. Anais... Campo Grande, 2000. v. 3.

RIO DE JANEIRO. Lei n. 2.393, de 20 de abril de 1995. Dispõe sobre a permanência de populações nativas residentes em unidades de conservação do Estado do Rio de Janeiro. Diário Oficial do Estado do Rio de Janeiro, abril de 1995.

RIO DE JANEIRO. Lei n. 3.443/2000. Regulamenta o artigo 27 das disposições transitórias e os artigos 261 e 271 da Constituição do Estado do Rio de Janeiro, estabelece a criação dos conselhos gestores para as unidades de conservação estaduais, e dá outras providências. Diário Oficial do Estado do Rio de Janeiro, junho de 2002.

SANQUETTA, C. R.; PIRES; P. T. L.; CRUZ, T. Reavaliação Técnico-Científica das Instruções Normativas IN DIRAM 100.001, 101.001, 101.004 e 101.007. Definição de Critérios de Identificação Tipológica para a Floresta Ombrófila Mista. 
Relatório Técnico-Científico. Curitiba: Fundação de Pesquisas Florestais do Paraná - Instituto Ambiental do Paraná, 2001.

SANTOS, A. J. Os Instrumentos Fiscais da Política Florestal Francesa. Rev. Floresta, Curitiba, n. 25, 1997. p. 71-77.

SILVA, J. A. Curso de Direito Constitucional

Positivo. 12. ed. São Paulo: Malheiros, 1996. 818 p. VENEZUELA. Decreto No 6.070, de 14 de mayo de
2008. Gaceta Oficial N ${ }^{\circ} 38.946$, Venezuela, 05 de junio de 2008. Ley de Bosques y Gestión Forestal. Ministerio del Poder Popular para el Ambiente. 68 p.

WHITMORE, T. C. An introduction to tropical rain forests. Oxford: Oxford University Press, 1990. $226 \mathrm{p}$.

WILlADINO, P. H. V. Mercosul - Legislação Florestal. IBAMA / CEDEFLOR, 1998. 455 p. 